\title{
Metalloproteinase 14 (MMP-14) and hsa-miR-410-3p expression in human inflamed dental pulp and odontoblasts
}

\author{
Aniela Brodzikowska ${ }^{1}$. Agata Gondek ${ }^{2} \cdot$ Beata Rak $^{2,4,5} \cdot$ Wiktor Paskal $^{2} \cdot$ Kacper Pełka $^{2}$. \\ Agnieszka Cudnoch-Jędrzejewska ${ }^{3} \cdot$ Paweł Włodarski $^{2}$
}

Accepted: 28 August 2019 / Published online: 5 September 2019

(c) The Author(s) 2019

\begin{abstract}
The objective of this study is to evaluate MMP-14 expression in odontoblasts and in the bulk of dental pulp of teeth with pulpitis; to determine the expression of microRNA-410 (miR-410) in pulp tissue, since sequence analysis suggests that miR410 has potential binding site on MMP-14's 3'UTR, and hence, can regulate expression of the latter one. Tissue samples of dental pulp from teeth with pulpitis and healthy (control) were formalin fixed and paraffin embedded (FFPE). Samples were examined using immunohistochemical staining for MMP-14 and the expression of miR-410 was evaluated using qRT-PCR. In both, healthy and inflamed pulp odontoblasts stained more intensively than remaining pulp tissue, but this difference was not statistically significant. More positive staining was observed in inflamed pulps compared to healthy pulps. Expression of miR-410 was found significantly lower in inflamed pulps than in healthy ones. In the two examined zones, odontoblasts and remaining pulp, miR-410 was expressed on a similar level. No statistically significant correlation of miR-410 and MMP-14 expression was found. We showed that inflammation changes the MMP-14 expression in pulp tissue and odontoblasts. This study demonstrates for the first time miR-410 expression in human dental pulp and that expression of this microRNA was downregulated in inflamed dental pulp and odontoblasts.
\end{abstract}

Keywords MMP-14 $\cdot$ microRNA-410 $\cdot$ Tooth pulp $\cdot$ Odontoblasts

\section{Introduction}

Pulpal inflammation is caused by microbes, and physical or chemical irritants. The pulp injury causes cellular damage and release of nonspecific proinflammatory mediators, e.g., histamine, bradykinin, neurokinins, and prostaglandins

Aniela Brodzikowska

nbrodzikowska@wp.pl

1 The Department of Conservative Dentistry, Medical University of Warsaw, Miodowa 18, 00-246 Warsaw, Poland

2 Laboratory of Centre for Preclinical Research, Department of Methodology, Medical University of Warsaw, Banacha 1b, 02-097 Warsaw, Poland

3 Laboratory of Centre for Preclinical Research, Department of Experimental and Clinical Physiology, Medical University of Warsaw, Banacha 1b, 02-097 Warsaw, Poland

4 Postgraduate School of Molecular Medicine, Medical University of Warsaw, Warsaw, Poland

5 Department of Internal Medicine and Endocrinology, Medical University of Warsaw, Banacha 1a, Warsaw, Poland
(Cooper et al. 2010). These factors cause vasodilatation, increased blood flow, exudate formation, and edema. The pulpal inflammation usually progresses slowly. Blood stasis leads to increased red blood cell aggregation, blood viscosity, and $\mathrm{CO}_{2}$ levels, as well as decreased $\mathrm{pH}$ levels and waste product removal. Carious enamel and dentin contain numerous bacteria capable of eliciting inflammatory reactions in pulp. These reactions are not often caused by direct exposure to bacteria, but instead to their toxins that penetrate via dentinal tubules into the pulp. The bacterial antigens and lipopolysaccharides (LPS) increase the levels of immunoglobulins, prostaglandins, and other proinflammatory mediators in the infected pulp (Nakanishi et al. 1995). Bacterial components and inflammatory factors stimulate the neutrophil degranulation and secretion by monocytes/macrophages (Chang et al. 2001; Lu et al. 2002). The released IL-1 and tumor necrosis factor- $\alpha$ (TNF- $\alpha$ ) are able to induce MMP-1, MMP-2, and the expression of tissue inhibitor for metalloproteinases-1 (TIMP-1) gene in pulpal cells (Chang et al. 2001; Lin et al. 2001). Stimulation by black-pigmented Bacteroides elevates MMP-2 production (Chang et al. 2002) 
and anaerobic bacterial extracts provoke pulp cells to excrete MMP-1 and MMP-2 as well as TIMP-1 (Nakata et al. 2000). The levels of MMP-1, -2, and -3 are significantly higher in acute pulpitis than in normal pulp tissue (Shin et al. 2002).

The most common cause of pulp inflammation and necrosis is caries. More than 460 bacterial taxa have been identified in endodontic infections (Siqueira and Rocas 2009). The tooth pulp is composed of connective tissue that contains numerous nerve fibers, vessels, and undifferentiated mesenchymal cells. The connective tissue core is surrounded by a layer of odontoblasts with their processes (Tomes' fibers) penetrating to dentinal tubules. Therefore, caries-induced inflammation initially affects odontoblasts-the outermost cells in the pulp (Love and Jenkinson 2002). It has been shown that the enzymatic degradation of the extracellular matrix (ECM) plays an important role in the development of inflammation (Gusman et al. 2002).

Matrix metalloproteinases (MMPs) form a group of proteases that belong to a family of structurally related zincdependent proteolytic enzymes known to play a key role in the catabolic turnover of extracellular matrix (ECM) and basement membrane (MB) components. MMPs are divided according to their substrate specificities and structures to interstitial collagenases, gelatinases, membrane-type MMPs, stromelysins, matrilysins, and other MMPs. MMPs regulate the activity of several non-ECM bioactive substrates including growth factors, cytokines, chemokines, and cell receptors with determining the tissue microenvironment. MMPs play a significant role in embryonal development, wound healing, and cell differentiation during tissue remodeling. The overexpression of several MMPs is involved in tumor invasion, metastasis, inflammation, and even cell destruction (Manicone and McGuire 2008). MMPs have recently been found also in pulpal tissue and odontoblasts, where they play a role in dentin matrix formation and modulation during caries progression and secondary dentin formation (Tjaderhane et al. 2001).

Cysteine cathepsin found in dentin has the ability to activate latent MMPs. The cathepsin activity increases with increasing depth of lesion. In carious lesions, cathepsin tends to influence the process through activation of latent MMPs. Most recent studies have indicated role of cysteine cathepsins in dentine caries by degradation of collagen through activating MMPs (Tjaderhane et al. 2013; Vidal et al. 2014).

In inflamed tissues, MMPs are synthesized both by structural cells (e.g., fibroblasts, keratinocytes, mast cells, osteoblasts, and odontoblasts), and by inflammatory cells (monocytes, macrophages, lymphocytes $\mathrm{T}$, and neutrophils) (Chaussain-Miller et al. 2006; Gusman et al. 2002). In pathological conditions (inflammation, cancer, and degenerative diseases), increased activity of MMPs is not effectively inhibited by the tissue inhibitors of metalloproteinases
(TIMPs). The result of this imbalance is the partial degradation of ECM and tissue injury (Baker et al. 2002).

Palosaari et al. have demonstrated the expression of following metalloproteinases in normal, mature human dental pulp: MMP-1, $-2,-9,-10,-11,-13,-14,-15,-16,-17,-19$, -20 , and -23 . Interestingly, MMP-7, $-8,-24$, and -25 were present exclusively in odontoblasts. It has been shown that expression of MMP $-2,-10,-11,-14$, and -20 was at least five times greater in odontoblasts than in remaining dental pulp cells (Palosaari et al. 2003). The authors suggested the potential role of MMP-14 in the activation of the other odontoblasts-derived MMPs. The expression of MMP-14 on the cell surface may initiate a cascade of proteases and the degradation of the ECM. It has also been demonstrated that the expression of MMP-14 in caries was increased in odontoblasts on the mRNA and protein level. However, the expression of MMP-14 was 13 times greater in odontoblasts than in the rest of the pulp (Palosaari et al. 2003). In pulpitis, an increased amount of MMP-2, -9 (Accorsi-Mendonca et al. 2013; Zehnder et al. 2011), MMP-8 (Wahlgren et al. 2002), and MMP-13 (Evrosimovska et al. 2012) was observed.

Metalloproteinase 14 (MMP-14), also called a membrane-type 1 metalloproteinase (MT1-MMP), is one of the metalloproteinases, which may play a critical role in healthy and inflamed pulp. Its structure contains a transmembrane domain, which passes through the cell membrane, and a short cytoplasmic C-terminal domain (Sternlicht and Werb 2001). MMP-14 directly cleaves components of the extracellular matrix, including fibronectin, collagen, and gelatin (Pei and Weiss 1996). It also activates pro-MMP-2 (HernandezBarrantes et al. 2000; Strongin et al. 1995) and takes part in the cell invasion to ECM (Nakahara et al. 1997). MMP-14 allows the cell migration, and like other metalloproteinases, plays an important role in tumor invasion and metastasis (Itoh and Seiki 2006; Sabeh et al. 2004). MMP-14 also can modulate inflammatory response of macrophages (ShimizuHirota et al. 2012). However, exact function of MMP-14 and other MMPs in the pulp and odontoblasts is unknown. The phenotype of MT1-MMP knockout mice partially explains the role of metalloproteinases in the development and growth of bones and teeth (Beertsen et al. 2002, 2003). The lack of such MMPs leads to reduction of the teeth growth and inhibition of bone formation (Beertsen et al. 2002, 2003).

MicroRNAs (miRNAs) are small non-coding RNA molecules, which bind to the 3'-untranslated region (UTR) of target messenger RNAs and consequently cause degradation of this mRNA or inhibit its translation (Ambros 2004). In result, miRNAs negatively regulate expression of targeted genes. MicroRNAs are involved in regulation of inflammation and immune response to bacterial infection of the dental pulp (Sonkoly et al. 2008). Modulated expression of miRNAs in the inflamed pulp of the tooth indicates that these molecules are involved in the inflammatory response 
in diseased dental pulp (Hui et al. 2017; Kong et al. 2014; Zhong et al. 2012, 2017). As previously shown, MMP-14 is potential target for hsa-miR-410-3p (miR-410) (Rak et al. 2016).

The aim of the study was to evaluate MMP-14 expression in odontoblasts and in the bulk of dental pulp of teeth with pulpitis. We analyzed also the expression of miR-410 in both zones of the tissue, since sequence analysis suggests that miR-410 has potential binding site on MMP-14's 3'UTR, and, hence, can regulate expression of the latter one (Rak et al. 2016).

\section{Materials and methods}

18 samples of dental pulp have been removed from the teeth extracted for orthodontic indications or have been extirpated from teeth with pulpits. Tissue samples were then formalin fixed and paraffin embedded (FFPE). Histopathological evaluation of HE-stained sections verified the correctness of clinical classification as an inflamed or healthy (control) pulp. Next, samples were examined using immunohistochemical staining and qRT-PCR. All experiments were performed in the Laboratory of Center for Preclinical Research of the Department of Methodology, Medical University of Warsaw.

\section{Immunohistochemistry}

Immunohistochemical staining (IHC) was performed on $10 \mu \mathrm{m}$ sections from FFPE tissues. Sections were deparaffinized according to standard protocol and antigens were retrieved in citrate buffer. The activity of endogenous peroxidase was diminished by incubation with $3 \%$ solution of hydrogen peroxide in methanol. To block nonspecific antibody binding, the sections were incubated with $2.5 \%$ normal horse serum for $40 \mathrm{~min}$. Then, sections were incubated overnight in a humid chamber with primary polyclonal antiMMP-14 antibody (cat no ab3644, Abcam, Cambridge, UK) in concentration $5 \mu \mathrm{g} / \mathrm{ml}$ at $4{ }^{\circ} \mathrm{C}$. At the same time, negative controls were incubated with blocking solution instead of the primary antibody. Incubation with peroxidase-conjugated secondary antibody (ImmPRESS ${ }^{\mathrm{TM}}$, catalog no MP-7401, Vector Laboratories, CA, USA) was carried out for $40 \mathrm{~min}$ at the room temperature. Reaction products were visualized by DAB chromogen (Dako Liquid DAB + Substrate Chromogen System, Dako, Denmark) and hematoxylin staining. The results were evaluated using microscope with scanning feature (PALM Robo, Carl Zeiss AG, Oberkochen, Germany). Sections were scanned with $20 \times$ objectives; images were stitched and processed with GIMP (The GIMP team, GIMP 2.8.10). The expression of MMP-14 was scored and quantified according to stain intensity using IHC Profiler in ImageJ (ImageJ v 1.48).

\section{Laser capture microdissection}

Laser capture microdissection (LCM) was performed on three healthy and three inflamed dental pulp tissue samples. Before the dissection, $10 \mu \mathrm{m}$ sections were stained with hematoxylin and eosin without mounting the cover glass. From each sample, $15 \mathrm{~mm}^{2}$ of odontoblasts or pulp tissue without odontoblasts were dissected into separate tubes (AdhesiveCap, Carl Zeiss AG, Oberkochen, Germany). RoboLPC mode was used for LCM (PALM Robo, Carl Zeiss AG, Oberkochen, Germany).

\section{MicroRNA isolation and qRT-PCR}

Total RNA was isolated from the excised tissues using RecoverALL Total Nucleic Acid Isolation Kit (Ambion ${ }^{\mathrm{TM}}$, Life Technologies, USA). Reverse transcription was performed with TaqMan miRNA primers and TaqMan microRNA Reverse Transcription Kit (Applied Biosystems, Life Technologies Corporation, USA). Expression of miR-410 was determined by real-time PCR using Taqman MicroRNA Assay (Assay ID 001274; miRBase Accession Number MI0002465; Stem-loop Sequence GGUACCUGAGAA GAGGUU-GUCUGUGAUGAGUUCGCUUUUAUUAAU GACGAAUAUAACACAGAUGGCCUGUUUUCAGUA CC; Applied Biosystems, Life Technologies Corporation, USA), sensiFAST Probe Lo-ROX Mix (Bioline, USA) with the Applied Biosystems 7500 Fast Real-Time PCR System, and 7500 Software V2.0.6 (Life Technologies Corporation 2011). U6 snRNA was used as an endogenous control (Assay ID 001973; NCBI Accession \# NR_004394; Control Sequence: GTGCTCGCTTCGGCAGCACATATACTAAAA TTGGAACGATA-CAGAGAAGATTAGCATGGCCCCTG CGCAAGGATGACACGCAAATTCGTGAAGCGTTC CATATTTT). PCR conditions were in accordance with the manufacturer's protocol. The relative expression of miR-410 was calculated automatically by the comparative $\mathrm{Ct}$ method.

\section{Statistics}

Analysis of IHC results and relative Ct from qRT-PCR were calculated with Excel 2016 (Microsoft Corporation, Redmond, WA, USA). Plots and statistical analysis of mir-410 expression and anti-MMP 14 staining including Wilcoxon signed-rank, $U$ Mann-Whitney, R Spearman's rank correlation, and one-way ANOVA tests were performed with Statistica 11 (Statsoft Inc., Dell Statistica, Tulsa, OK, USA) and the GraphPad Prism statistics software (GraphPad Prism 6, San Diego, CA, USA). The $p$ value of $<0.05$ was considered statistically significant. 


\section{Results}

\section{MMP-14 expression in healthy and inflamed dental pulp}

The assessment of expression of MMP-14 was performed on 12 tissue samples by immunohistochemical staining. In both, healthy and inflamed pulp odontoblasts stained more intensively than remaining pulp tissue, but this difference was statistically insignificant ( $p=0.071$, Wilcoxon signedrank test). More positive staining was observed in inflamed pulps compared to healthy pulps (Fig. 1). The quantitative analysis of the MMP-14 staining intensity of healthy and inflamed pulps is presented in Fig. 2. Although the
Fig. 1 Healthy (a-d) and inflamed (e-h) dental pulp. Each specimen was obtained from distinct patient. Immunohistochemical staining for MMP-14. Scale bar $=5 \mu \mathrm{m}$

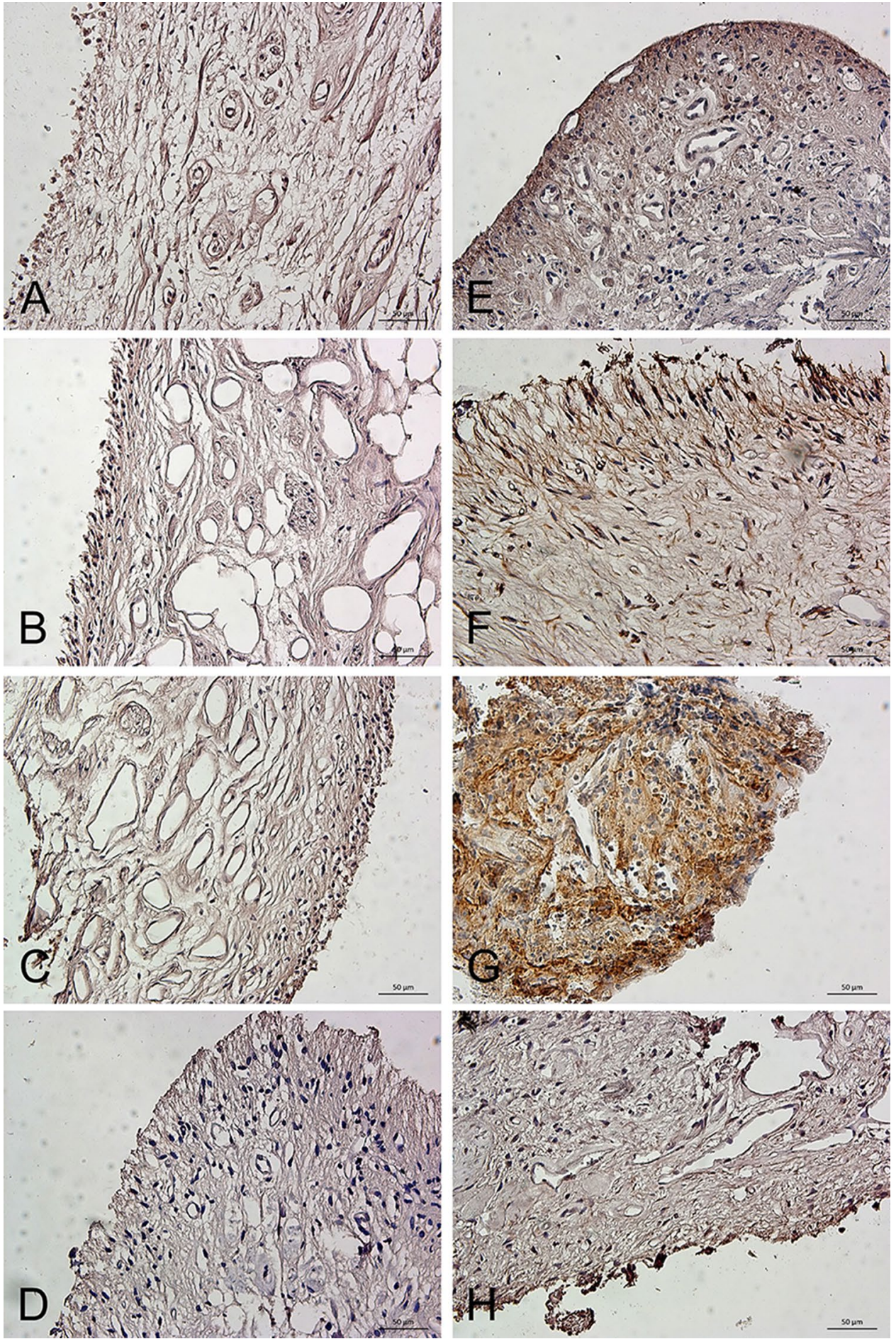


expression of MMP-14 was higher in inflamed pulps, these differences are statistically insignificant ( $U$ Mann-Whitney and ANOVA tests).

\section{miR-410 expression in odontoblasts and dental pulp tissue}

The miR-410 expression in healthy and inflamed pulp tissue is presented in Fig. 3. Expression of this microRNA was significantly lower in inflamed pulps than in healthy ones $p=0.0021$ and $p=0.0025$ (Mann-Whitney $U$ and oneway ANOVA test). The analysis of the miR-410 expression both in odontoblasts and pulp tissue is shown in Fig. 4. In the two examined zones, odontoblasts and remaining pulp, miR-410 was expressed on a similar level $p>0.05$ (Wilcoxon signed-rank test). However, no statistically significant correlation of miR-410 and MMP-14 expression was found ( $r=-0.028, p>0.05, R$ Spearman's rank correlation test) neither in healthy nor in inflamed pulp.

\section{Discussion}

The inflammation of the pulp usually results when bacterial toxins pass through dentin and reach the pulp (BirkedalHansen 1995). The increased levels of MMPs in inflamed pulp suggest that MMPs play an important role in the extracellular tissue degradation and in the disease progression. On the other hand, MMPs are important mediators during physiological tissue remodeling (Jain and Bahuguna 2015), being a key component of the local protective mechanisms of the dentin-pulp complex in cases of inflammation. Most likely MMPs play a role during the inflammation of the pulp

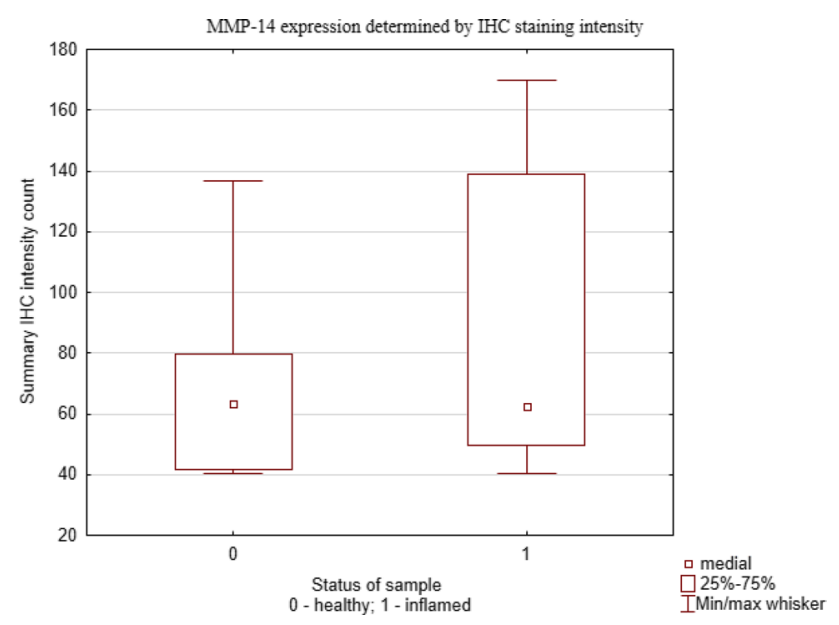

Fig. 2 The quantitative analysis of MMP-14 expression determined by IHC staining intensity in healthy and in inflamed pulp tissue by IHC Profiler in ImageJ (ImageJ v 1.48)

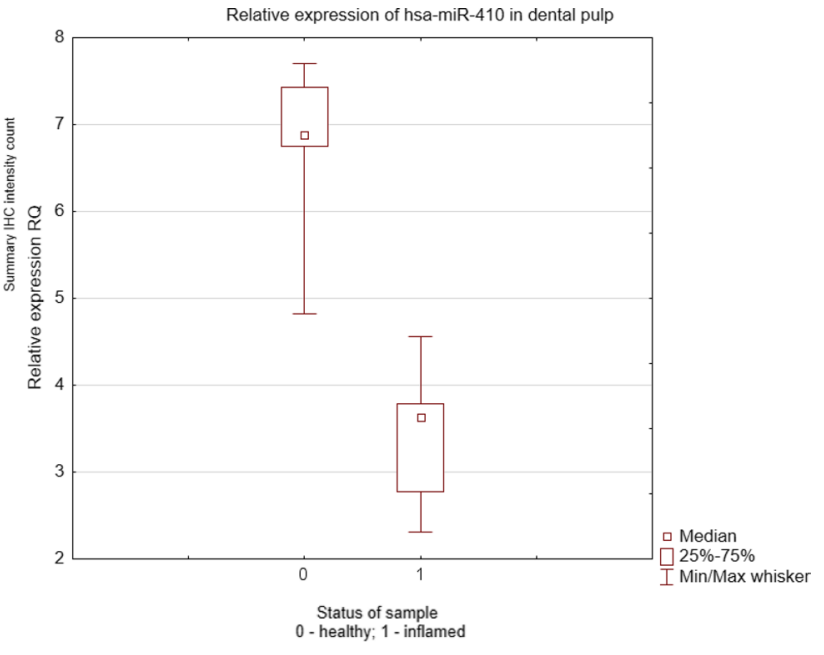

Fig. 3 miR-410 expression level in healthy and inflamed pulp tissue. The expression of miR-410 was determined by qRT-PCR with U6 as an endogenous control and calculated by the comparative CT method

by mediating in the disintegration of the pulp connective tissue, which enables odontoblast-like cells to migrate and form reparative dentin (Evrosimovska et al. 2012).

The understanding of the role of MMP activity in the oral environment is incomplete without discussing the formation of human caries lesions. In dental caries, demineralization is caused by microbial acids, and degradation of dentinal organic matrix was thought to be carried out solely by microbial proteolytic enzymes responsible for the degradation of dentine organic matrix. Presence of both preand active forms of MMP-8, MMP-2, and MMP-9 in human dental carious lesions suggests; however, their active role in the process. MMP-8, MMP-2, MMP-3, MMP-9, MMP-14,

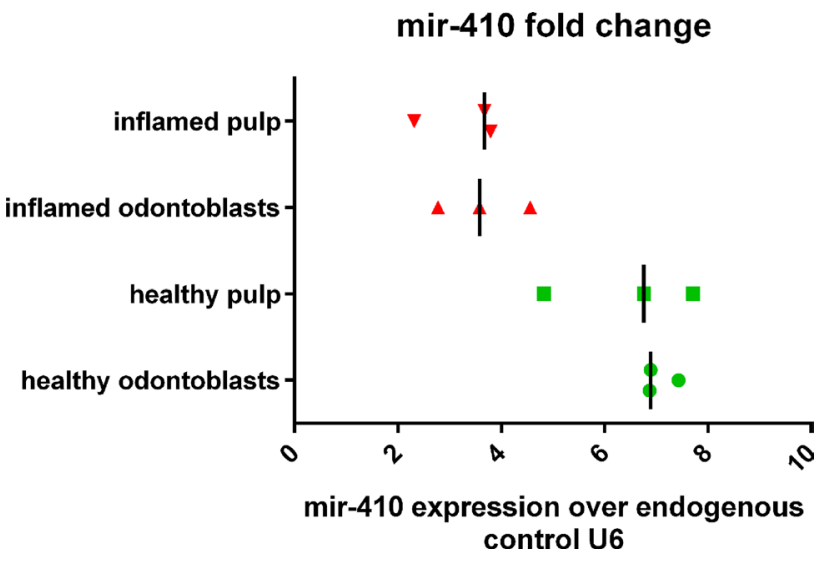

Fig. 4 The relative level of the miR-410 expression over the endogenous control U6. The graph shows distinction into different subgroups: healthy, inflamed, pulp and odontoblasts. Median value is signed with line. The total level of the miR-410 expression in inflamed tissue was lower compared to healthy ones 
and MMP-20 are the main MMPs identified in pulp, odontoblasts, predentine, and dentine (Sulkala et al. 2004, 2007). MMP activity has been found to decrease with age in both active and chronic carious lesions (Nascimento et al. 2011).

Salivary MMPs also tend to have a significant contribution towards dentine matrix degradation during the carious process. Endogenous MMP-2 contained in sound dentine is activated during the carious process. Caries also tends to increase the level of endogenous MMP-2 synthesis. Acidic $\mathrm{pH}$ of carious dentin may both induce MMP production by the odontoblasts as well as their activation, thereby potentiating MMP proteolytic capacity, leading to enhanced dentine matrix degradation (Toledano et al. 2010).

Sorsa et al. demonstrated the contribution of both proand active forms of MMP-8, -2 , and -9 . After the demineralization of dentin by bacterial acids, enzymes contained in plaque and saliva and produced by odontoblasts break down the dentine matrix, consisting of collagen type I and small amounts of collagen type V. Non-collagenous proteins, including dentine matrix protein I, osteopontin, and dentine sialoprotein, have also been suggested as activators of MMP pro-forms taking part in dentin matrix degradation (Sorsa et al. 2004).

MMP-14 cleaves the collagen type I, II, and III, fibronectin, laminin 1 and 5, vitronectin, and proteoglycan (Koshikawa et al. 2004; Ohuchi et al. 1997). By contrast, it does not degrade type IV collagen, the main component of the basement membrane, but activates pro-MMP-2, which is capable of doing this (Okada et al. 1990).

In this study, the expression of MMP-14 in the pulp was evaluated by immunohistochemical staining. MMP-14 expression was found to be higher in inflamed pulp than healthy one. Also odontoblasts layer stained more intensively than other pulp tissue cells. These results, however, were not statistical significant, which may be due to the relative small number of samples. The presence of MMP-14 was demonstrated in mature human dental pulp and odontoblasts by Palosaari et al. (2002). These authors suggested the potential role of MMP-14 in the activation of the other odontoblast-derived MMPs. The expression of MMP-14 on the cell surface may initiate a cascade of proteases and degradation of ECM. It has also been demonstrated that in caries, the expression of MMP-14 was increased in odontoblasts on mRNA and protein level (Charadram et al. 2012). MMP-14 was upregulated during the formation of reactionary dentin.

MMP-14, besides pro-MMP-2 (Lehti et al. 1998), also activates pro-MMP-13 (Cowell et al. 1998; Knauper et al. 1996) and pro-MMP-20 (Palosaari et al. 2003). For example, MMP-13, also known as collagenase-3, degrades various components of the basement membrane and is highly effective in digestion of collagen type II (Jain and Bahuguna 2015). It was found that MMP-13 in rat pulp injury model plays critical roles in angiogenesis and pulp wound healing (Zheng et al. 2009). Whereas the study of Sulkala et al. (2002) demonstrates that in the external irritation, MMP-20 in dentin fluid originates from odontoblast and is secreted in tubular dentine. Therefore, MMP-20 may be involved in the defense responses; for example, the formation of secondary dentine, but may also be a component of the normal dentinal fluid. In addition, Giannelli et al. (1997) demonstrated that MMP-2 cleaves laminin 5 and plays a crucial role in cell migration during tissue remodeling and tumor invasion. Thus modifications of extracellular matrix components are necessary for cell migration. It has also been suggested that MMP-14 is essential for cell migration over laminin 5, while MMP-2, activated by MMP-14, plays an auxiliary role and may amplifying MMP-14 effects (Koshikawa et al. 2000, 2004).

All of the data discussed above show that various proteases are engaged in pulpitis, nonetheless, our present study was limited to examine solely the expression of MMP-14. Many studies point to altered expression of miR-410 in a variety of tumors (Guo et al. 2015; Li et al. 2015; Palumbo et al. 2016; Shen et al. 2014; Wang et al. 2014, 2016; Zhang et al. 2016), which proves its participation in their development as well as in tumor metastasis. Inflammation also affects the expression of microRNA. Zhong et al. (2012) determined the expression of miRNAs in healthy and inflamed human dental pulps and found that 33 miRNAs were downregulated in inflammatory pulps. In our study, mir-410 was also downregulated in the inflamed pulps. According to other study on miR-410, this molecule acts as an inflammatory suppressor via NF- $\mathrm{KB}$ signaling pathway and HMGB-1 (Wang et al. 2019; Xiong et al. 2017). Recently, examined intranasal administration of synthetic mir-410 led to reduced inflammation in asthmatic mice through IL4 and IL-13 depletion (Jin et al. 2019). These studies not only explain observed downregulation in inflamed dental pulp, but also increase the importance of explaining the role of mir410 in dental pulpitis as a potential, direct anti-inflammatory target. However, there was not any significant correlation between expression of MMP-14 and miR-410 in human dental pulp. We are aware that this finding may be the result of the small number of studied samples in each group. In current report, we confirmed overexpression of MMP-14 on 12 samples, while mir- 410 was studied on six tissue samples (three healthy and three inflamed with the distinction to pulp and odontoblasts). Results presented in this report are in accordance with our previous findings in endometrial cancer (Rak et al. 2016).

To the best of our knowledge, this is the first study that demonstrates miR-410 expression in human dental pulp. We have shown here the expression pattern of MMP-14 in human dental pulp and odontoblasts in both: healthy and inflamed pulp and illustrated how inflammation changes the 
MMP-14 expression in pulp tissue including odontoblasts. MMP-14, due to its ability to activate another pro-MMPs, may have a crucial role during extracellular matrix remodeling an inflammation. The expression of miR-410 was downregulated in inflamed dental pulp and odontoblasts. These findings confirmed the intricate and specific role of miR-410 as an inflammation inhibitor and suggest that this microRNA must also play a role in pulpitis pathogenesis. Further research is needed to elucidate the targets by which miR-410 can potentially modulate the host response in pulpal disease.

Funding No funding.

\section{Compliance with ethical standards}

Conflict of interest All authors declare that they have no conflict of interests.

Ethical approval This article does not contain any studies with human participants or animals performed by any of the authors.

Informed consent For this type of study, formal consent is not required.

Open Access This article is distributed under the terms of the Creative Commons Attribution 4.0 International License (http://creativeco mmons.org/licenses/by/4.0/), which permits unrestricted use, distribution, and reproduction in any medium, provided you give appropriate credit to the original author(s) and the source, provide a link to the Creative Commons license, and indicate if changes were made.

\section{References}

Accorsi-Mendonca T et al (2013) Evaluation of gelatinases, tissue inhibitor of matrix metalloproteinase-2, and myeloperoxidase protein in healthy and inflamed human dental pulp tissue. J Endod 39:879-882. https://doi.org/10.1016/j.joen.2012.11.011

Ambros V (2004) The functions of animal microRNAs. Nature 431:350-355. https://doi.org/10.1038/nature02871

Baker AH, Edwards DR, Murphy G (2002) Metalloproteinase inhibitors: biological actions and therapeutic opportunities. J Cell Sci 115:3719-3727. https://doi.org/10.1242/jcs.00063

Beertsen W, Holmbeck K, Niehof A, Bianco P, Chrysovergis K, Birkedal-Hansen H, Everts V (2002) On the role of MT1MMP, a matrix metalloproteinase essential to collagen remodeling, in murine molar eruption and root growth. Eur J Oral Sci 110:445-451

Beertsen W, Holmbeck K, Niehof A, Bianco P, Chrysovergis K, Birkedal-Hansen H, Everts V (2003) Inhibition of molar eruption and root elongation in MT1-MMP-deficient mice. Connect Tissue Res 44(Suppl 1):298-299

Birkedal-Hansen H (1995) Proteolytic remodeling of extracellular matrix. Curr Opin Cell Biol 7:728-735

Chang YC, Yang SF, Hsieh YS (2001) Regulation of matrix metalloproteinase-2 production by cytokines and pharmacological agents in human pulp cell cultures. J Endod 27:679-682. https:// doi.org/10.1097/00004770-200111000-00007

Chang YC, Lai CC, Yang SF, Chan Y, Hsieh YS (2002) Stimulation of matrix metalloproteinases by black-pigmented bacteroides in human pulp and periodontal ligament cell cultures. J Endod 28:90-93. https://doi.org/10.1097/00004770-200202000-00010

Charadram N, Farahani RM, Harty D, Rathsam C, Swain MV, Hunter N (2012) Regulation of reactionary dentin formation by odontoblasts in response to polymicrobial invasion of dentin matrix. Bone 50:265-275. https://doi.org/10.1016/j.bone.2011.10.031

Chaussain-Miller C, Fioretti F, Goldberg M, Menashi S (2006) The role of matrix metalloproteinases (MMPs) in human caries. J Dent Res 85:22-32. https://doi.org/10.1177/154405910608500104

Cooper PR, Takahashi Y, Graham LW, Simon S, Imazato S, Smith AJ (2010) Inflammation-regeneration interplay in the dentinepulp complex. J Dent 38:687-697. https://doi.org/10.1016/j.jdent .2010.05.016

Cowell $\mathrm{S}$ et al (1998) Induction of matrix metalloproteinase activation cascades based on membrane-type 1 matrix metalloproteinase: associated activation of gelatinase A, gelatinase B and collagenase 3. Biochem J 331(Pt 2):453-458. https://doi.org/10.1042/bj331 0453

Evrosimovska B, Dimova C, Kovacevska I, Panov S (2012) Concentration of collagenases (MMP-1, -8, -13) in patients with chronically inflamed dental pulp tissue. Prilozi 33:191-204

Giannelli G, Falk-Marzillier J, Schiraldi O, Stetler-Stevenson WG, Quaranta V (1997) Induction of cell migration by matrix metalloprotease-2 cleavage of laminin-5. Science 277:225-228. https ://doi.org/10.1126/science.277.5323.225

Guo R, Gu J, Zhang Z, Wang Y, Gu C (2015) MicroRNA-410 functions as a tumor suppressor by targeting angiotensin II type 1 receptor in pancreatic cancer. IUBMB Life 67:42-53. https://doi. org/10.1002/iub.1342

Gusman H, Santana RB, Zehnder M (2002) Matrix metalloproteinase levels and gelatinolytic activity in clinically healthy and inflamed human dental pulps. Eur J Oral Sci 110:353-357

Hernandez-Barrantes $\mathrm{S}$ et al (2000) Binding of active (57 kDa) membrane type 1-matrix metalloproteinase (MT1-MMP) to tissue inhibitor of metalloproteinase (TIMP)-2 regulates MT1-MMP processing and pro-MMP-2 activation. J Biol Chem 275:1208012089. https://doi.org/10.1074/jbc.275.16.12080

Hui T, Wang C, Chen D, Zheng L, Huang D, Ye L (2017) Epigenetic regulation in dental pulp inflammation. Oral Dis 23:22-28. https ://doi.org/10.1111/odi.12464

Itoh Y, Seiki M (2006) MT1-MMP: a potent modifier of pericellular microenvironment. J Cell Physiol 206:1-8. https://doi. org/10.1002/jcp.20431

Jain A, Bahuguna R (2015) Role of matrix metalloproteinases in dental caries, pulp and periapical inflammation: an overview. J Oral Biol Craniofac Res 5:212-218. https://doi.org/10.1016/j.jobcr .2015.06.015

Jin R, Hu S, Liu X, Guan R, Lu L, Lin R (2019) Intranasal instillation of miR410 targeting IL4/IL13 attenuates airway inflammation in OVA induced asthmatic mice. Mol Med Rep 19:895-900. https ://doi.org/10.3892/mmr.2018.9703

Knauper V et al (1996) Cellular mechanisms for human procollagenase-3 (MMP-13) activation. Evidence that MT1-MMP (MMP-14) and gelatinase a (MMP-2) are able to generate active enzyme. J Biol Chem 271:17124-17131. https://doi.org/10.1074/ jbc.271.29.17124

Kong Q, Liu L, Huang Y, Zhang F, Wei X, Ling J (2014) The effect of octamer-binding transcription factor $4 \mathrm{~B} 1$ on microRNA signals in human dental pulp cells with inflammatory response. J Endod 40:101-108. https://doi.org/10.1016/j.joen.2013.09.030

Koshikawa N, Giannelli G, Cirulli V, Miyazaki K, Quaranta V (2000) Role of cell surface metalloprotease MT1-MMP in epithelial cell migration over laminin-5. J Cell Biol 148:615-624. https://doi. org/10.1083/jcb.148.3.615 
Koshikawa N et al (2004) Proteolytic processing of laminin-5 by MT1-MMP in tissues and its effects on epithelial cell morphology. FASEB J 18:364-366. https://doi.org/10.1096/fj.03-0584fje

Lehti K, Lohi J, Valtanen H, Keski-Oja J (1998) Proteolytic processing of membrane-type-1 matrix metalloproteinase is associated with gelatinase A activation at the cell surface. Biochem $\mathrm{J} 334(\mathrm{Pt}$ 2):345-353. https://doi.org/10.1042/bj3340345

Li D, Yang Y, Zhu G, Liu X, Zhao M, Li X, Yang Q (2015) MicroRNA-410 promotes cell proliferation by targeting BRD7 in nonsmall cell lung cancer. FEBS Lett 589:2218-2223. https://doi. org/10.1016/j.febslet.2015.06.031

Lin SK, Wang CC, Huang S, Lee JJ, Chiang CP, Lan WH, Hong CY (2001) Induction of dental pulp fibroblast matrix metalloproteinase- 1 and tissue inhibitor of metalloproteinase- 1 gene expression by interleukin-1alpha and tumor necrosis factor-alpha through a prostaglandin-dependent pathway. J Endod 27:185-189. https:// doi.org/10.1097/00004770-200103000-00012

Love RM, Jenkinson HF (2002) Invasion of dentinal tubules by oral bacteria. Crit Rev Oral Biol Med 13:171-183

Lu HX, Xiao MZ, Niu ZY, Guo XM, Zhao SL, Wang HG, Guo HY (2002) Effect of IL-1ra on human dental pulp cells and pulpal inflammation. Int Endod J 35:807-811

Manicone AM, McGuire JK (2008) Matrix metalloproteinases as modulators of inflammation. Semin Cell Dev Biol 19:34-41. https:// doi.org/10.1016/j.semcdb.2007.07.003

Nakahara H, Howard L, Thompson EW, Sato H, Seiki M, Yeh Y, Chen WT (1997) Transmembrane/cytoplasmic domain-mediated membrane type 1-matrix metalloprotease docking to invadopodia is required for cell invasion. Proc Natl Acad Sci USA 94:7959-7964. https://doi.org/10.1073/pnas.94.15.7959

Nakanishi T, Matsuo T, Ebisu S (1995) Quantitative analysis of immunoglobulins and inflammatory factors in human pulpal blood from exposed pulps. J Endod 21:131-136

Nakata K, Yamasaki M, Iwata T, Suzuki K, Nakane A, Nakamura H (2000) Anaerobic bacterial extracts influence production of matrix metalloproteinases and their inhibitors by human dental pulp cells. J Endod 26:410-413. https://doi.org/10.1097/00004770-20000 7000-00008

Nascimento FD et al (2011) Cysteine cathepsins in human carious dentin. J Dent Res 90:506-511. https://doi.org/10.1177/00220 34510391906

Ohuchi E, Imai K, Fujii Y, Sato H, Seiki M, Okada Y (1997) Membrane type 1 matrix metalloproteinase digests interstitial collagens and other extracellular matrix macromolecules. J Biol Chem 272:2446-2451. https://doi.org/10.1074/jbc.272.4.2446

Okada $Y$ et al (1990) Matrix metalloproteinase 2 from human rheumatoid synovial fibroblasts. Purification and activation of the precursor and enzymic properties. Eur J Biochem 194:721-730. https:// doi.org/10.1111/j.1432-1033.1990.tb19462.x

Palosaari H, Ding Y, Larmas M, Sorsa T, Bartlett JD, Salo T, Tjaderhane L (2002) Regulation and interactions of MT1-MMP and MMP-20 in human odontoblasts and pulp tissue in vitro. J Dent Res 81:354-359. https://doi.org/10.1177/154405910208100513

Palosaari H, Pennington CJ, Larmas M, Edwards DR, Tjaderhane L, Salo T (2003) Expression profile of matrix metalloproteinases (MMPs) and tissue inhibitors of MMPs in mature human odontoblasts and pulp tissue. Eur J Oral Sci 111:117-127

Palumbo T et al (2016) A functional microRNA library screen reveals miR-410 as a novel anti-apoptotic regulator of cholangiocarcinoma. BMC Cancer 16:353. https://doi.org/10.1186/s1288 5-016-2384-0

Pei D, Weiss SJ (1996) Transmembrane-deletion mutants of the membrane-type matrix metalloproteinase- 1 process progelatinase A and express intrinsic matrix-degrading activity. J Biol Chem 271:9135-9140. https://doi.org/10.1074/jbc.271.15.9135
Rak B, Garbicz F, Paskal W, Pelka K, Marczewska JM, Wolosz D, Wlodarski P (2016) The expression of MMP-14 and microRNA-410 in FFPE tissues of human endometrial adenocarcinoma. Histol Histopathol 31:911-920. https://doi.org/10.14670 /hh-11-728

Sabeh F et al (2004) Tumor cell traffic through the extracellular matrix is controlled by the membrane-anchored collagenase MT1-MMP. J Cell Biol 167:769-781. https://doi.org/10.1083/jcb.200408028

Shen J, Niu W, Zhou M, Zhang H, Ma J, Wang L, Zhang H (2014) MicroRNA-410 suppresses migration and invasion by targeting MDM2 in gastric cancer. PLoS One 9:e104510. https://doi. org/10.1371/journal.pone.0104510

Shimizu-Hirota R et al (2012) MT1-MMP regulates the PI3Kdelta. $\mathrm{Mi}-2 / \mathrm{NuRD}-d e p e n d e n t$ control of macrophage immune function. Genes Dev 26:395-413. https://doi.org/10.1101/gad.178749.111

Shin SJ, Lee JI, Baek SH, Lim SS (2002) Tissue levels of matrix metalloproteinases in pulps and periapical lesions. J Endod 28:313-315. https://doi.org/10.1097/00004770-200204000-00013

Siqueira JF Jr, Rocas IN (2009) Diversity of endodontic microbiota revisited. J Dent Res 88:969-981. https://doi.org/10.1177/00220 34509346549

Sonkoly E, Stahle M, Pivarcsi A (2008) MicroRNAs and immunity: novel players in the regulation of normal immune function and inflammation. Semin Cancer Biol 18:131-140. https://doi. org/10.1016/j.semcancer.2008.01.005

Sorsa T, Tjaderhane L, Salo T (2004) Matrix metalloproteinases (MMPs) in oral diseases. Oral Dis 10:311-318. https://doi.org/ 10.1111/j.1601-0825.2004.01038.x

Sternlicht MD, Werb Z (2001) How matrix metalloproteinases regulate cell behavior. Annu Rev Cell Dev Biol 17:463-516. https://doi. org/10.1146/annurev.cellbio.17.1.463

Strongin AY, Collier I, Bannikov G, Marmer BL, Grant GA, Goldberg GI (1995) Mechanism of cell surface activation of 72-kDa type IV collagenase. Isolation of the activated form of the membrane metalloprotease. J Biol Chem 270:5331-5338. https://doi. org/10.1074/jbc.270.10.5331

Sulkala M, Larmas M, Sorsa T, Salo T, Tjaderhane L (2002) The localization of matrix metalloproteinase-20 (MMP-20, enamely$\sin$ ) in mature human teeth. J Dent Res 81:603-607. https://doi. org/10.1177/154405910208100905

Sulkala M, Paakkonen V, Larmas M, Salo T, Tjaderhane L (2004) Matrix metalloproteinase-13 (MMP-13, collagenase-3) is highly expressed in human tooth pulp. Connect Tissue Res 45:231-237. https://doi.org/10.1080/03008200490885788

Sulkala M, Tervahartiala T, Sorsa T, Larmas M, Salo T, Tjaderhane L (2007) Matrix metalloproteinase-8 (MMP-8) is the major collagenase in human dentin. Arch Oral Biol 52:121-127. https://doi. org/10.1016/j.archoralbio.2006.08.009

Tjaderhane L, Palosaari H, Wahlgren J, Larmas M, Sorsa T, Salo T (2001) Human odontoblast culture method: the expression of collagen and matrix metalloproteinases (MMPs). Adv Dent Res 15:55-58. https://doi.org/10.1177/08959374010150011401

Tjaderhane L et al (2013) Optimizing dentin bond durability: control of collagen degradation by matrix metalloproteinases and cysteine cathepsins. Dent Mater 29:116-135. https://doi.org/10.1016/j. dental.2012.08.004

Toledano M, Nieto-Aguilar R, Osorio R, Campos A, Osorio E, Tay FR, Alaminos M (2010) Differential expression of matrix metalloproteinase-2 in human coronal and radicular sound and carious dentine. J Dent 38:635-640. https://doi.org/10.1016/j.jdent .2010.05.001

Vidal CM et al (2014) Abundance of MMPs and cysteine cathepsins in caries-affected dentin. J Dent Res 93:269-274. https://doi. org/10.1177/0022034513516979

Wahlgren J, Salo T, Teronen O, Luoto H, Sorsa T, Tjaderhane L (2002) Matrix metalloproteinase-8 (MMP-8) in pulpal and periapical 
inflammation and periapical root-canal exudates. Int Endod J 35:897-904

Wang Y et al (2014) MiR-410 is overexpressed in liver and colorectal tumors and enhances tumor cell growth by silencing FHL1 via a direct/indirect mechanism. PLoS One 9:e108708. https://doi. org/10.1371/journal.pone.0108708

Wang J et al (2016) MicroRNA-410-5p as a potential serum biomarker for the diagnosis of prostate cancer. Cancer Cell Int 16:12. https ://doi.org/10.1186/s12935-016-0285-6

Wang Y, Xu N, Zhao S, Jiao T, Fu W, Yang L, Zhang N (2019) miR410-3p suppresses cytokine release from fibroblast-like synoviocytes by regulating NF-kappaB signaling in rheumatoid arthritis. Inflammation 42:331-341. https://doi.org/10.1007/s1075 3-018-0896-2

Xiong J et al (2017) MicroRNA-410-3p attenuates gemcitabine resistance in pancreatic ductal adenocarcinoma by inhibiting HMGB1mediated autophagy. Oncotarget 8:107500-107512. https://doi. org/10.18632/oncotarget.22494

Zehnder M, Wegehaupt FJ, Attin T (2011) A first study on the usefulness of matrix metalloproteinase 9 from dentinal fluid to indicate pulp inflammation. J Endod 37:17-20. https://doi.org/10.1016/j. joen.2010.10.003
Zhang X et al (2016) MicroRNA-410 acts as oncogene in NSCLC through downregulating SLC34A2 via activating Wnt/betacatenin pathway. Oncotarget 7:14569-14585. https://doi. org/10.18632/oncotarget. 7538

Zheng L et al (2009) Matrix metalloproteinase-3 accelerates wound healing following dental pulp injury. Am J Pathol 175:1905-1914. https://doi.org/10.2353/ajpath.2009.080705

Zhong S, Zhang S, Bair E, Nares S, Khan AA (2012) Differential expression of microRNAs in normal and inflamed human pulps. J Endod 38:746-752. https://doi.org/10.1016/j.joen.2012.02.020

Zhong S, Naqvi A, Bair E, Nares S, Khan AA (2017) Viral MicroRNAs identified in human dental pulp. J Endod 43:84-89. https://doi. org/10.1016/j.joen.2016.10.006

Publisher's Note Springer Nature remains neutral with regard to jurisdictional claims in published maps and institutional affiliations. 